\title{
The Relations Among Multicultural Adolescents' Trauma, Emotion Regulation, and Problem Behaviors in South Korea
}

\author{
Kyungsook Kim ${ }^{1}$, Min-Jung $\mathrm{Kim}^{2 *}$, Minkyeong $\mathrm{Kim}^{3}$, Sejin Ju, ${ }^{4}$ and Eun-Jee Song ${ }^{5}$ \\ ${ }^{1,4}$ Department of Nursing, Namseoul University,91, Daehak-ro, Seonghwan-eup, \\ Sebuk-gu, Cheonan-si, Chungcheongnam-do 31020, South Korea \\ ${ }^{2,3}$ Department of Child Welfare, Namseoul University, Korea \\ ${ }^{5}$ Department of Compute Science, Namseoul University, Korea \\ ${ }^{1}$ kgs4321@nsu.ac.kr, ${ }^{2 *}$ Corresponding Author: longmin@nsu.ac.kr, \\ ${ }^{3}$ mkm35@nsu.ac.kr, ${ }^{4}$ lovepdd@nsu.ac.kr, ${ }^{5}$ sej@nsu.ac.kr
}

\begin{abstract}
The purpose of this study was to examine the relations among multicultural adolescents' trauma, emotion regulation, and problem behaviors. The research subjects consisted of 28 adolescents (boys $=15$, girls=13) from multicultural families. They were middle/high school students aged between 13 and 20. The measures of the current study include scales for assessing adolescents' trauma, emotion regulation, and problem behaviors. The data were analyzed by t-tests, Pearson correlations, and SPSS 21.0 program. Results demonstrated that multicultural adolescents' trauma, emotion regulation, and problem behaviors were significantly correlated.
\end{abstract}

Keywords: Multicultural, Adolescents, Trauma, Emotion, Regulation, Problem, Behaviors

\section{Introduction}

Our society has converted to multicultural society rapidly. According to the report of the Education Ministry, the number of multicultural students has become 82,536. This means a $14,530(18 \%)$ increase compared to the previous year. During 5 years, the number of middle/high school of multicultural students has increased more than 10 times. Therefore, this study will inspect the correlation among the conflicts of identity which was caused by difference of culture, experience of discrimination, emotional regulation, and problem behaviors.

Multicultural youths show a denial feature because of bicultural atmosphere. They have not adopted themselves and harmonized with Korean culture. Further, they have various kinds of hardship including low status of their parents, descents of poverty, and dullness of learning. In this bicultural atmosphere, their parents' sense of values and lifestyles make them confronted with many troubles. In particular, they have gone through what was violated by teachers or friends. Maladjustment which occurred by process of physical, social, and mental growth became more serious than general youth. In addition to this, the troubles of emotional behavior are influenced by discriminating experiences [1].

Multicultural youth will grow as members of society through interaction with family, friends, and school. However, these kinds of prejudice and discrimination put their health, emotion, and behavior in danger seriously. During their childhood and adolescence, the

Article history:

Received (July 31, 2016), Review Result (September 01, 2016), Accepted (October 03, 2016) 
damage of trauma that they experienced can lead to depression, anxiety, emotional uneasiness, trouble of a social nature [2], and internalizing and externalizing problems [3]. In other words, if they have experienced a variety of social prejudice and stress, they go through depression more than the general youth [4]. Leaving alone their depression could lead to adulthood depression and severe problematic behaviors. When they fail to control their emotion such as depression, anger, etc., they may manifest problematic behavior [5]. Therefore, in this study, we are going to look at references to control emotion and problem behaviors.

\section{Methods}

\subsection{Participants}

The research subjects consisted of 28 adolescents (boys=15, girls=13) from multicultural families who were middle/high school students aged between 13 and 20. The research subjects were gathered by contacting relevant organizations and schools located in areas where the proportion of multi-cultural families was large.

\subsection{Measures}

The measures of the current study include scales for assessing adolescents' trauma, emotion regulation, and problem behaviors. All scales were self-reported questionnaires. The full range of response categories was as follows: not at all (1), a little (2), quite a bit (3), and very much (4).

\subsubsection{Trauma}

Trauma was measured by the Impact of Event Scale-Revised, which was translated by Lee and used by Lee [6]. This scale is composed of 22 items. The items ask the respondents to indicate the frequency of each symptom. Cronbach's $\alpha$ of the total internal consistency was .93 .

\subsubsection{Emotion regulation}

Emotion regulation was assessed by the Emotion Regulation Checklist (ERC) used by Park [3], which was developed by Yoon and then supplemented by Lim. The scale consists of three subscales: active regulation style ( 8 items; $\alpha=.75$ ), support-seeking regulation style ( 8 items, $\alpha=.66$ ), and avoidant/distractive regulation style (9 items, $\alpha=.62$ ). The items describe the means with which the respondents may try to reduce their negative emotions.

\subsubsection{Problem behaviors}

Adolescent problem behaviors were measured by a scale used by Park, which adapted Achenbach's scale developed for measuring children's and adolescents' behavioral and emotional problems to measure internal and external problem behaviors. The current scale, composed of 64 items, measures two aspects of problem behaviors: internal and external problem behaviors. The internal problem behaviors (34 items) consist of withdrawn (9 items, $\alpha=.83$ ), somatic complaints (9 items, $\alpha=.79$ ), and anxious/depressed (17 items, $\alpha=.92$ ), while the external problem behaviors are composed of delinquent behavior (11 items, $\alpha=.90)$ and aggressive behavior (19 items, $\alpha=.92$ ). 


\subsection{Procedures}

The researchers acquired permissions from the administrators of the relevant multicultural family organizations and schools. With the help of social workers, the purposes of this research were explained to the adolescents of the multicultural families and the completed questionnaires were obtained. Before completing the questionnaires, consent forms were distributed to the participants to explain the purposes and content of the current study. Only the participants who signed the consent form became the subjects of this study. During the research processes, the research subjects were able to withdraw whenever they wanted, in which event their questionnaires were discarded immediately. The surveyors were thoroughly informed of the appropriate processes regarding research ethics.

\subsection{Data analysis}

The data from the current study were analyzed by SPSS 21.0 program. First, to examine the research subjects' socioeconomic characteristics, the frequency and probability of the cases were evaluated. To ascertain the reliability of measurements, Cronbach's alphas were calculated and t-test was performed in order to determine whether each other variable was significantly different according to trauma. Finally, the correlation analysis was conducted to examine the relations between the variables.

\section{Results}

\subsection{Demographic characteristics of the research subjects}

The demographic characteristics of the research subjects were recorded. The multicultural adolescents consisted of 15 boys (53.3\%) and 13 girls (46.4\%). Ten were aged 16 years old (35.7\%), five were 17 years old (17.9\%), five were 19 years old (17.9\%), three were 18 years old $(10.7 \%)$, two were 15 years old $(7.1 \%)$, two were 20 years old $(7.1 \%)$, and one was 13 years old $(3.6 \%)$. The average ages of fathers and mothers were 46.2 years $(S D=5.34)$ and 43.7 years $(S D=5.62)$, respectively. In terms of nationality, 27 had fathers who were South Koreans while 1 had a father from China; 15 had a mother from China, 5 had a mother from Russia, 2 had a mother from Kazakhstan, while 1 had a mother from either Uzbekistan, Ukraine, or the Republic of the Philippines. Approximately 11 fathers dropped out of junior high school or graduated (39.3\%), while 6 fathers were either a high school dropout or graduate $(21.4 \%)$. As for the mothers' educational level, 12 subjects had a mother who was either a high school dropout or graduate $(42.9 \%)$ and 7 had a mother who was either a junior high school dropout or graduate $(25.0 \%)$. Seven fathers $(25.0 \%)$ worked in the agricultural or manufacturing industry and six fathers $(21.4 \%)$ were service-employed. In the case of the mothers, six mothers $(21.4 \%)$ were service-employed and four (14.3\%) were office workers.

\subsection{Trauma and counseling path}

The kinds of trauma experienced by the multi-cultural adolescents are presented in [Table 1]. Multicultural adolescents checked all of experienced traumas and the results were as follows. 
The Relations among Multicultural Adolescents' Trauma, Emotion Regulation, and Problem Behaviors in South Korea

Table 1. The frequency of trauma and counseling $(\mathrm{N}=28)$

\begin{tabular}{|c|c|c|c|}
\hline Trauma & $N(\%)$ & Counseling & $N(\%)$ \\
\hline School violence & $6(21.4)$ & Parents & $10(35.7)$ \\
\hline Bullying & $3(10.7)$ & Friends, colleagues & $21(75.0)$ \\
\hline Sexual violence & $15(53.6)$ & Juniors and seniors & $1(3.6)$ \\
\hline Domestic violence & $1(3.6)$ & Teacher & $15(53.6)$ \\
\hline Discrimination at home & $1(3.6)$ & Youth consultants & $1(3.6)$ \\
\hline Discrimination at school & $15(53.6)$ & Themselves & $6(21.4)$ \\
\hline Discrimination in society & $4(14.3)$ & Others & $13(46.4)$ \\
\hline Others & $13(46.4)$ & & - \\
\hline
\end{tabular}

Note: Frequency $(\%)$ is the answer including duplicates.

\subsection{Differences in multicultural adolescents' trauma, emotion regulation, and problem behaviors}

The differences in multicultural adolescents' trauma, emotion regulation, and problem beh aviors are presented in [Table 2]. The higher trauma group reported lower emotion regulation and higher problem behaviors compared to the lower trauma group.

Table 2. Differences in multicultural adolescents' trauma, emotion regulation, and problem behaviors

$(\mathrm{N}=28)$

\begin{tabular}{|c|c|c|c|c|c|}
\hline & Variables & Group & M & SD & $\mathrm{t}$ \\
\hline \multirow{6}{*}{$\begin{array}{l}\text { motion } \\
\text { Regulation }\end{array}$} & \multirow{2}{*}{$\begin{array}{l}\text { Active } \\
\quad \text { regulation style }\end{array}$} & $\operatorname{High}(\mathrm{n}=19)$ & 2.92 & .48 & \multirow{2}{*}{-1.18} \\
\hline & & $\operatorname{Low}(\mathrm{n}=8)$ & 3.15 & .40 & \\
\hline & \multirow{2}{*}{$\begin{array}{l}\text { Support-seeking } \\
\text { regulation style }\end{array}$} & $\operatorname{High}(\mathrm{n}=19)$ & 2.77 & .43 & \multirow{2}{*}{$-2.08^{*}$} \\
\hline & & $\operatorname{Low}(\mathrm{n}=8)$ & 3.16 & .48 & \\
\hline & \multirow{2}{*}{$\begin{array}{l}\text { Avoidant/distractive } \\
\text { regulation style }\end{array}$} & $\operatorname{High}(\mathrm{n}=19)$ & 2.74 & .43 & \multirow{2}{*}{.98} \\
\hline & & $\operatorname{Low}(n=8)$ & 2.56 & .37 & \\
\hline \multirow{10}{*}{$\begin{array}{l}\text { Problem } \\
\text { Behaviors }\end{array}$} & \multirow{2}{*}{ Withdrawn } & $\operatorname{High}(\mathrm{n}=19)$ & 2.37 & .45 & \multirow{2}{*}{$4.06^{* * *}$} \\
\hline & & $\operatorname{Low}(\mathrm{n}=8)$ & 1.54 & .57 & \\
\hline & \multirow{2}{*}{ Somatic Complaints } & $\operatorname{High}(n=19)$ & 2.42 & .46 & \multirow{2}{*}{$4.31^{* * *}$} \\
\hline & & $\operatorname{Low}(\mathrm{n}=8)$ & 1.60 & .44 & \\
\hline & \multirow{2}{*}{ Anxious/Depressed } & $\operatorname{High}(\mathrm{n}=19)$ & 2.31 & .50 & \multirow{2}{*}{$4.20^{* * *}$} \\
\hline & & $\operatorname{Low}(n=8)$ & 1.50 & .31 & \\
\hline & \multirow{2}{*}{ Delinquent Behavior } & $\operatorname{High}(\mathrm{n}=19)$ & 2.23 & .62 & \multirow{2}{*}{$5.08^{* * * *}$} \\
\hline & & $\operatorname{Low}(n=8)$ & 1.33 & .30 & \\
\hline & \multirow{2}{*}{ AggressiveBehavior } & $\operatorname{High}(n=19)$ & 2.21 & .51 & \multirow{2}{*}{$3.79^{* *}$} \\
\hline & & $\operatorname{Low}(\mathrm{n}=8)$ & 1.48 & .30 & \\
\hline
\end{tabular}

\subsection{Correlations among multicultural adolescents' trauma, emotion regulation, and Problem behaviors}

The correlations in multicultural adolescents' trauma, emotion regulation, and problem behaviors are presented in [Table 3]. Trauma wasn't significantly correlated to emotion 
regulation, but it was significantly correlated to all problem behaviors ( $r=.473$ to .719 ). In case of emotion regulation, active regulation style had significantly negative correlation to delinquent behavior $(r=-.458, p<.05)$ and aggressive behaviors $(r=-.477, p<.05)$ and supportseeking regulation style had significantly negative correlation to all problem behaviors $(r=-$ .432 to -.641$)$.

Table 3. Correlations among multicultural adolescents' trauma, emotion regulation, and problem behaviors $(\mathrm{N}=28)$

\begin{tabular}{|c|c|c|c|c|c|c|c|c|c|}
\hline Variables & 1 & 2 & 3 & 4 & 5 & 6 & 7 & 8 & 9 \\
\hline Trauma & 1 & & & & & & & & \\
\hline \multicolumn{10}{|l|}{ Emotion Regulation } \\
\hline $\begin{array}{l}\text { 1. Active regulation } \\
\text { style }\end{array}$ & $\begin{array}{l}.0 \\
09\end{array}$ & 1 & & & & & & & \\
\hline $\begin{array}{l}\text { 2. Support-seeking } \\
\text { regulation style }\end{array}$ & $\begin{array}{l}- \\
.24 \\
9\end{array}$ & $.495^{* *}$ & 1 & & & & & & \\
\hline $\begin{array}{l}\text { 3.Avoidant/distractive } \\
\text { regulation style }\end{array}$ & $\begin{array}{c}.24 \\
6\end{array}$ & .246 & .148 & 1 & & & & & \\
\hline \multicolumn{10}{|c|}{ Problem Behaviors } \\
\hline 1. Withdrawal & .69 & -.050 & $-.432^{*}$ & .116 & 1 & & & & \\
\hline 2. SomaticComplaints & .71 & -.114 & $-.466^{*}$ & .221 & $.753^{* *}$ & 1 & & & \\
\hline 3.Anxiety/Depression & $\begin{array}{l}.51 \\
3^{* * * *}\end{array}$ & -.289 & $\begin{array}{c}- \\
.574^{* *}\end{array}$ & .119 & $.823^{* *}$ & $.805^{* *}$ & 1 & & \\
\hline $\begin{array}{l}\text { 4. Delinquent } \\
\text { Behavior }\end{array}$ & $\begin{array}{l}.47 \\
3^{*}\end{array}$ & $-.458^{*}$ & $\begin{array}{c}- \\
.641^{* *} \\
*\end{array}$ & .012 & $.680^{* *}$ & $\begin{array}{c}755^{* *} \\
*\end{array}$ & $\begin{array}{c}886^{* *} \\
*\end{array}$ & 1 & \\
\hline 5. AggressiveBehavior & $\begin{array}{l}.52 \\
0^{* *}\end{array}$ & $-.477^{*}$ & $\begin{array}{c}- \\
.552^{* *}\end{array}$ & .110 & $.665^{* *}$ & $.726^{* *}$ & $.823^{* *}$ & $.850^{* * *}$ & 1 \\
\hline$M$ & $\begin{array}{c}2.3 \\
8\end{array}$ & 2.98 & 2.88 & 2.69 & 2.15 & 2.20 & 2.10 & 1.98 & 2.04 \\
\hline$S D$ & .64 & .45 & .46 & .38 & .41 & .61 & .59 & .68 & .60 \\
\hline
\end{tabular}

\section{Conclusions}

This research was attempted to find out the trauma level of multicultural adolescents and to discover the differences of emotion regulation and problem behaviors according to trauma level. As to trauma experience, discrimination at school and sexual violence consisted $53.6 \%$; this was the highest proportion. The next was violence at school with $21.4 \%$ followed by discrimination in society with $14.3 \%$. These results indicated that most discrimination and violence experiences occurred under the school environment. That is the reason that school has a crucial role in the education and development for multicultural adolescents and they spend lots of time at school.

The prior researches reported multicultural youths as subjects of bullying and violence or isolation and teased at school and who had a lot of experiences as regards fighting or bullying and violence. The results suggest the necessity of continuous intervention and support such as 
education or group consultation programs for adolescents that experienced trauma. The sexual violence among multicultural youths was relatively high. It means that that can cause developmental and social problems. The sexual violence experience has fatal and negative effects, has a long-term influence in their lifetime, and is a very serious problem. In fact, violence experience in childhood has negative effects on one's physical body, psychological development, behaviors, and developmental characteristics in contrast with those of other children, having lasting effect until adulthood [7][8][9][10].

Therefore, based on these findings, the trauma experiences of multicultural adolescents showed that discrimination and violence experience mainly resulted from school or society. Thus, intervention for adolescents should involve peers and teachers, as well as multicultural youth. Also, there is a need for a support system and the creation of a climate for a nondiscriminating society.

\section{Acknowledgements}

This research was supported financially by the National Research Fund in South Korea (NRF: 20161A5B6913928).

\section{References}

[1] S. Y. Kim, "The effect of complex trauma in childhood on the emotional behavioral problem for college students, Focused on the mediating effects of coping flexibility," M.S. thesis, Catholic University, Korea, (2016)

[2] H. J. Jang, "The effect of the characteristic of victims and child abuse," Journal of Korean Council for Children \& Rights, vol.8, no.4, pp.777-792, (2004)

[3] S. Y. Park, H. S. Doh, M. J. Kim, and S. M. Song, "The effects of maternal grandmothers' positive parenting behavior, mothers' emotion regulation and positive parenting behavior on children's emotion regulation," Korean Journal of Child Studies, vol.35, no.2, pp.117-136, (2014)

[4] J. H. Park and J. S.Nam, "Language development and psychosocial adjustment of multicultural children," Studies on Korean Youth, vol.21, no.2, pp.129-152, (2010)

[5] M. H. Kim, B. S. Kim, and J. Y. Choi, "The relations of attention, executive functions, emotion regulation to behavioral problems of children and adolescents with ADHD," Journal of Emotional \& Behavioral Disorders, vol.31, no.3, pp.537-551, (2015)

[6] Y.Lee, "The attachment-cognitive model of posttraumatic growth: Finding from the birthmothers sample," Ph.D. dissertation, Korea University, Korea, (2010)

[7] J. Y.Kim, H. S.Doh, and M. J.Kim, "Problem behavior of preschool children: The influence of marital conflict and of children's temperament and emotion regulation," Korean Journal of Child Studies, vol.29, no.5, pp.133-150, (2008)

[8] K. A. Dodge, J. E. Bates, and G. S. Pettit, "Mechanisms in the cycle of violence," Science, vol.250, pp.16781683, (1990) DOI:10.1126/science.2270481

[9] K. H.Kim, "Effects of child abuse and neglect on child development," Journal of Social Sciences, vol.24, no.2, pp.27-45, (2009)

[10] A. Anthonysamy and M. J. Zimmer-Gembeck, "Peer status and behaviors of maltreated children and their classmates in the early years of school," Child Abuse \& Neglect, vol.25, no.1, pp.13-31, (2007) DOI:10.1016/j.chiabu.2007.04.004 